\title{
Reliability of long-term monitoring data
}

\author{
Peter Anderegg • Rolf Brönnimann • \\ Urs Meier
}

Received: 18 October 2012/Revised: 16 April 2013/Accepted: 20 April 2013/Published online: 2 June 2013

(C) Springer-Verlag Berlin Heidelberg 2013

\begin{abstract}
Increasing loads, aging, new construction materials like CFRP (carbon fiber reinforced polymers) and also cost pressure are influences for fitness of traffic infrastructures, especially bridges. Prolonged health monitoring can be a means to compete with these challenges. The lifetime of infrastructure can reach 100 years, while that of sensors is typically much shorter. Therefore, sensors need to be long-term qualified and might have to be replaced by new sensors or even another sensor system during the life cycle of a structure. A reliable system for data acquisition and data analysis will be essential: Do the measurement data really relate to the monitored infrastructure and are not an effect of the degradation of the sensing system? We discuss measurement uncertainty and reliability of data obtained by different sensor types, including resistance strain gages, fiber optical sensors and other sensors systems which are in service up to 17 years.
\end{abstract}

Keywords Long-term - Health monitoring · Infrastructure - Reliability - Carbon fiber reinforced polymers (CFRP) · Fiber optical sensor (FOS) · Fiber bragg grating (FBG) - Resistance strain gages (RSG) - Sensor · Data acquisition

\section{Introduction}

Different reasons lead to an increasing demand on health monitoring of traffic infrastructures, mainly

P. Anderegg $(\bowtie) \cdot$ R. Brönnimann · U. Meier

Empa, Swiss Federal Laboratories for Materials

Science and Technology, 8600 Dübendorf, Switzerland

e-mail: peter.anderegg@empa.ch bridges for rail and road. Due to heavier vehicles and denser traffic, infrastructure is exposed to higher loads than they were designed for. New materials like CFRP and other composites have to be tested for their longterm behavior [1-3]. And for economic reasons the service life of bridges should be extended [4, 5]. Therefore, the question arises regarding how reliable monitoring can be achieved for infrastructure which is designed for a service life up to 100 years [6-8]. Regarding the long service life of the structures, availability and maintainability are very important as well but not a topic of this paper. Since usual sensor systems have a much shorter life time, two approaches seem to be successful: measuring systems have to be designed for long-term use, i.e., the systems have to be maintainable and adequate measures shall reduce the failure probability of components. In addition, reliable dataacquisition-systems and data analysis as well as the knowledge of the long-term behavior of sensors are essential [9-12]. It has to be known whether the measured data relate to the monitored infrastructure or are derived from the degradation of the sensors.

The long-term measurements described in the following sections were made over a period of up to 17 years. Well established and newly developed sensor systems like linear variable differential transformer (LVDT), resistance strain gages (RSGs), fiber Bragg grating sensors (FBGs), temperature and humidity sensors have been used. The three monitored bridges vary from a new cable-stayed bridge for cars, a new pedestrian bridge to a retrofitted bridge for cars. All bridges were monitored to study the behavior of CFRP cables. This paper discusses the results of the long-term measuring uncertainty and long-term reliability of the in situ measurements and parallel reference measurements in the lab. 


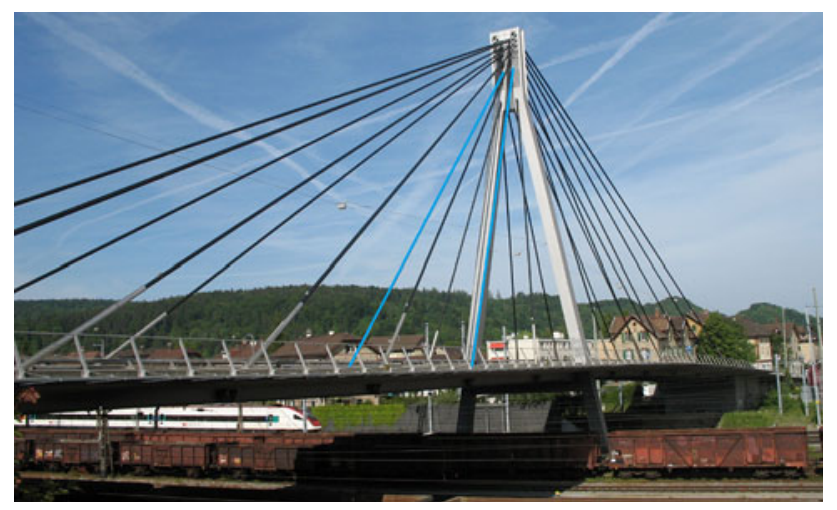

Fig. 1 Cable-stayed bridge Storchenbruecke with the two 35-m long CFRP-cables K43 (left) and K44 (right)

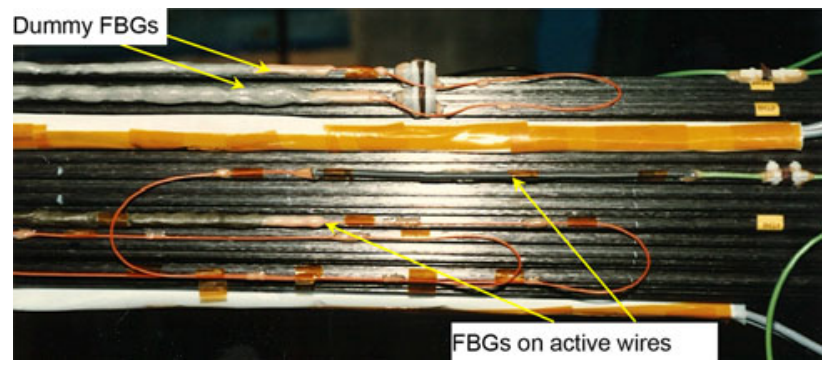

Fig. 2 Some of the 241 CFRP-wires with attached FBG- and RSGsensors (RSGs not seen in the figure)

\section{The bridges, measuring methods and results}

\subsection{Storchenbruecke, Winterthur (Switzerland)}

This symmetric cable-stayed bridge was built in 1996 and it has been monitored since then [13]. It has a length of $120 \mathrm{~m}$ and is crossing 18 railway tracks. Two of the 24 cables were made of CFRP (Fig. 1), each consisting of 241 CFRP-wires, $5 \mathrm{~mm}$ in diameter.

To measure the wire strain, RSGs and FBGs were surface adhered to loaded wires and to unloaded dummy wires for temperature compensation (Fig. 2). Three of the FBGs were attached pre-strained on dummy wires with strains' levels around $2,500 \mu \mathrm{m} / \mathrm{m}$. Strain decay on these FBGs, e.g., due to creep or delamination, is a strong indication for the loss of long-term stability of the measurement system. As discussed in more detail below no significant difference between the drift of strained and unstrained dummies could be observed verifying its long-term stability. The FBGs and their application are described in [14] and a broader discussion of the general use of FBGs in structural health monitoring can be found e.g., in [15-19].

For the RSG-measurement $6 \mathrm{~mm}$-long gages of the type LY51-6/120 from HBM were applied to the CFRP-wires with a cyanoacrylate based, cold curing adhesive (HBM: Z70). To protect the RSGs against environmental influences, two covering agents were used: the first layer is a plastic putty (HBM: AK22) and the second a silicon rubber (HBM: SG250). For the measurement a Wheatstone bridge was built, consisting of a loaded RSG, an unloaded RSG and paired precision resistors (M + M: H2-120-01). The bridge is read out by a carrier frequency amplifier $(1 \mathrm{~V}, 4.8 \mathrm{kHz})$. Special "quad-shielded" twisted pair cables (HBM, $3 \times 2 \times 0.14 \mathrm{~mm}^{2}$ ) have been used to minimize the noise pick up of the up-to 100-m-long feed lines.

The mean cable load of approximately $1,000 \mathrm{kN}$ is quite moderate. This corresponds to an average strain of about $1,200 \mu \mathrm{m} / \mathrm{m}$ on each CFRP-wire. To measure the relative displacement between the anchorage cone and the CFRP parallel wire bundle (pull-in) a displacement sensor with RSGs based on a bending spring element was developed.

Compared to the steel cables, the axial thermal expansion of the CFRP-cables is negligible. Therefore, raising temperature shifts load from the steel cables to the CFRPcables. The temperature-induced load variation of the

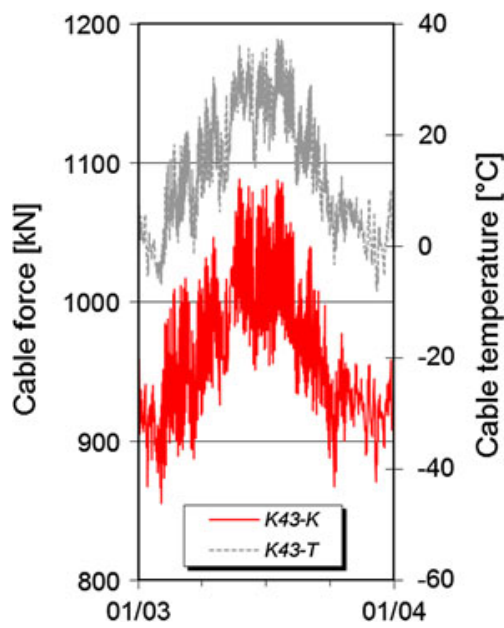

Fig. 3 One-year-graph of a typical RSG-measurement on cable K43

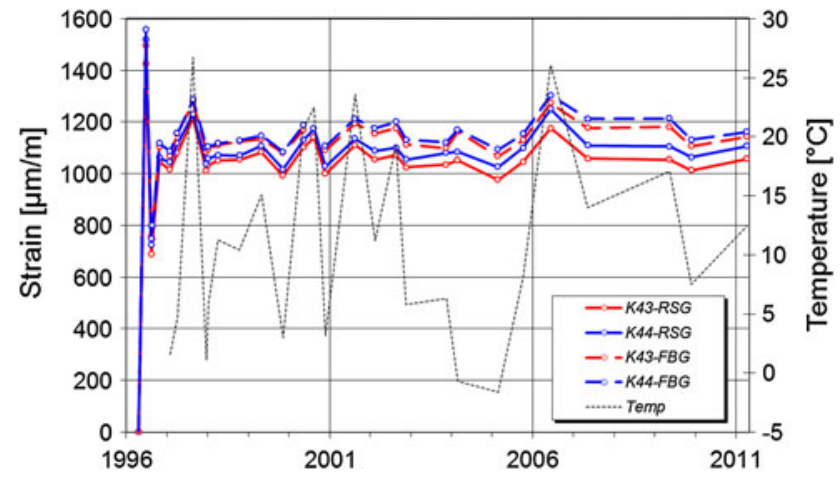

Fig. 4 RSG (solid line) and FBG (dashed line) measurements of average strain on the CFRP-wires of cables K43 and K44 including the pretensioning phase 
CFRP is about $25 \%$ of the pretension. Figure 3 shows 3-h mean values of the cable force obtained from the RSGmeasurement of a typical year with a temperature span of approximately $45^{\circ} \mathrm{C}$. In Fig. 4, RSG- and FBG-measurements are compared for a time span of 15 years. The correlation of these two completely independent measurement systems is very good. FBG-measurements have been done at irregular intervals.

Figure 5 shows the difference between the RSGs and FBGs for the two CFRP cables. The scatter can be attributed to time delay between RSG and FBG measurement and measurement uncertainties. What remains is a drift of about $3 \mu \mathrm{m} / \mathrm{m} /$ year. This is mainly due to the drift of the RSGs since we can estimate the negligible long-term drift of the FBGs as follows: the measured strain change of the

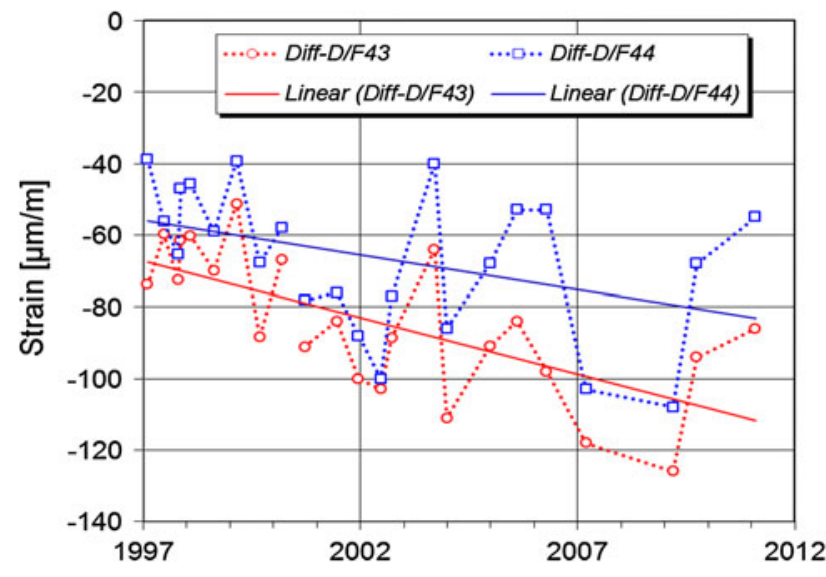

Fig. 5 The difference between strains of RSG- and FBG-measurements (shown in Fig. 4) on cable K43 (red lines) and K44 (blue lines) resp.

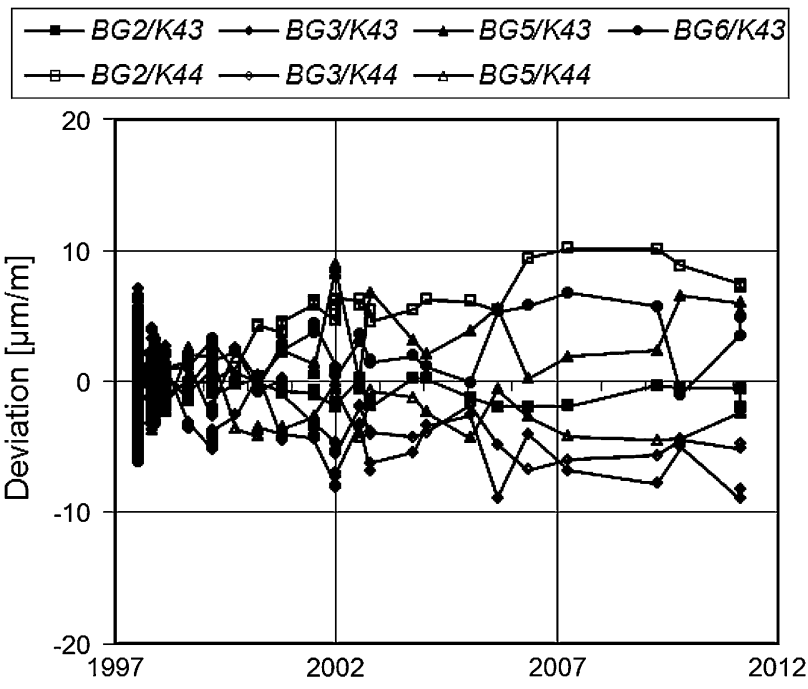

Fig. 6 Deviation of FBGs on dummy wires from mean value (BGx/ Kyy: x FBG number, yy cable number (43 or 44 , resp.) dummy FBGs should be zero in a perfect system. In a real system the values scatter and show possibly a drift. From this data, we can estimate a measurement uncertainty (one standard deviation) of about $3 \mu \mathrm{m} / \mathrm{m}$ (see scatter of the seven dummy FBGs in Fig. 6). Assuming a constant drift the slope for the dummy FBG can be calculated. Over 15 years the absolute value of the slope is well below $1 \mu \mathrm{m} / \mathrm{m} /$ year for each individual FBG. In addition, the signs of the slopes do not correlate with the pre-strain state of the dummies. Hence, we can state that the limit of the strain decay rate of pre-strained dummies is below this tight limit and also for the active FBGs on the cables almost no drift is expected.

In contrast to the FBGs no information of the stability drift of the RSGs is available. Possible reasons for the higher RSG-drift were not examined further. Since the reference measurements in a testing machine with almost eight times higher strains than in the field application showed a very low drift (Fig. 12), it cannot be explained with the strain level. It is assumed that the continuous change of temperature and humidity causes the RSG drift. In respect to reliability it can be stated, that in the last 17 years none of the 14 FBGs failed, 4 of 18 RSGs failed, three RSGs simultaneously-most probably caused by a lightning.

After the initial tensioning of the cables, only a small increase of the relative displacement between the anchorage cone and the CFRP parallel wire bundle can be observed. In contrast to the cable loads, this process is independent of the temperature and increases at about $0.1 \mathrm{~mm}$ per year (Fig. 7). The drift of the reference sensor in the laboratory is shown in Fig. 8. It can be interpreted as an overlay of an exponential decaying and a linear drift of about $2 \mu \mathrm{m}$ per year. For the long-term behavior only the linear part is essential and is below the required long-term

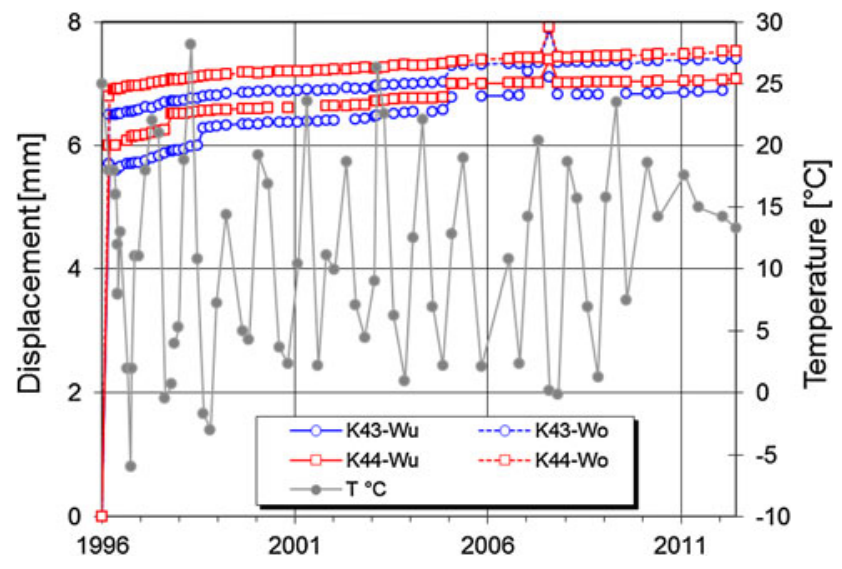

Fig. 7 Pull-in at the top end of the cables (K43-Wo/K44-Wo) and the lower end $(\mathrm{K} 43-\mathrm{Wu} / \mathrm{K} 44-\mathrm{Wu})$ between anchorage and CFRP-wire bundle is inclusive of the pretensioning and construction phase 
stability to monitor this measurand. The origin of the described drift has not been further investigated yet.

\subsection{Bridge Kleine Emme, Lucerne (Switzerland)}

This bridge is a 47-m-long steel-concrete-composite bridge for pedestrians and bicycles constructed in 1998 and monitored since then. Two CFRP-cables with 91 wires were installed under the bridge deck for pretensioning (Fig. 9). Each cable was prestressed with $2,400 \mathrm{kN}-$ which corresponds to a stress level of approx. 1,350 MPa,

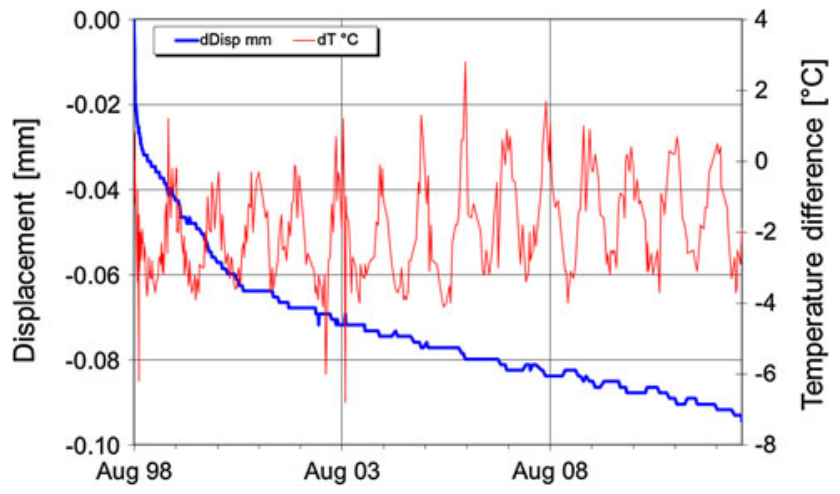

Fig. 8 Drift of the displacement sensor under laboratory condition

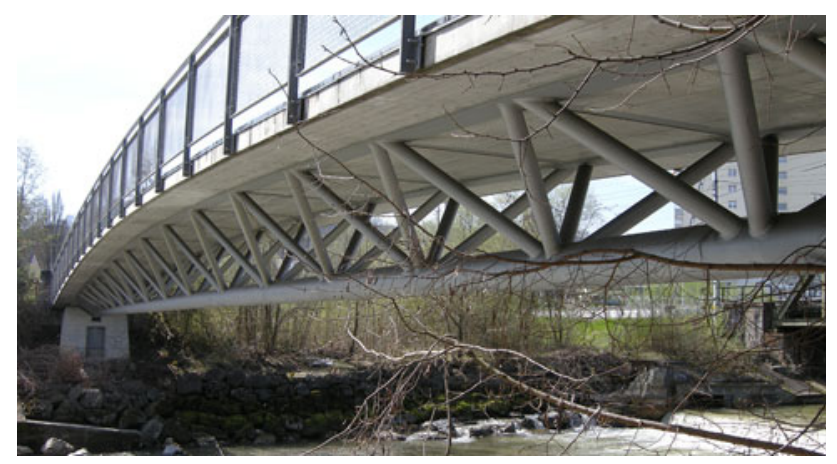

Fig. 9 The 47-m-long steel-concrete-composite bridge with the tube containing the two CFRP-cables corresponding to a high strain level of about $8,500 \mu \mathrm{m} / \mathrm{m}$ on the CFRP-wires. Therefore, it was of high interest to monitor the wire strains not only in the free part of the cable, but also within the anchor head. To transfer safely such high strains to the anchor head it was designed to linearly decrease the strain in the wires [1]. FBGs inside the head allowed this design to be verified (Fig. 10). To measure the strains in the wire the FBGs were directly embedded in the CFRP-wires during the industrial pultrusion process - the first application of this kind. The directly embedded FBGs allowed locating them inside the anchor, and hence to acquire the important information about axial strain distribution during the pretensioning phase and operation. In the case of this bridge, 8 of 21 FBGs failed due to high strain levels in combination with an embedding process that should be optimized. The failures occurred outside the anchor heads. Many of the RSGs initially attached on the wires in the free part of the cable failed during the pretensioning process. Therefore, additional RSGs were retrofitted on the steel anchor heads-to obtain redundant information about force variation.

At the bridge Kleine Emme similar effects from the daily and seasonal temperature changes can be observed like at Storchenbruecke. The elongation of the steel tube which contains the two CFRP-cables produces a force change within a band width below $10 \%$ of the pretension force. Figure 11 shows a comparison of the calculated forces obtained from the three different strain measuring methods with FBGs and RSGs on the CFRP-wires and RSGs on the steel sleeves. Even though these are not synchronized measurements, the strains correspond within a bandwidth of $1 \%$ of the tensioning load.

The reference measurement with RSGs on a CFRP-wire in a testing machine under a constant load of $32 \mathrm{kN}$ and unloaded dummy RSGs showed a high stability—only small residual temperature variations affected the results. Figure 12 shows the strain to load ratio: the standard deviation is $0.5 \mu \mathrm{m} / \mathrm{m} / \mathrm{kN},<0.1 \%$ of the load. This verifies the very good long-term laboratory stability of the common

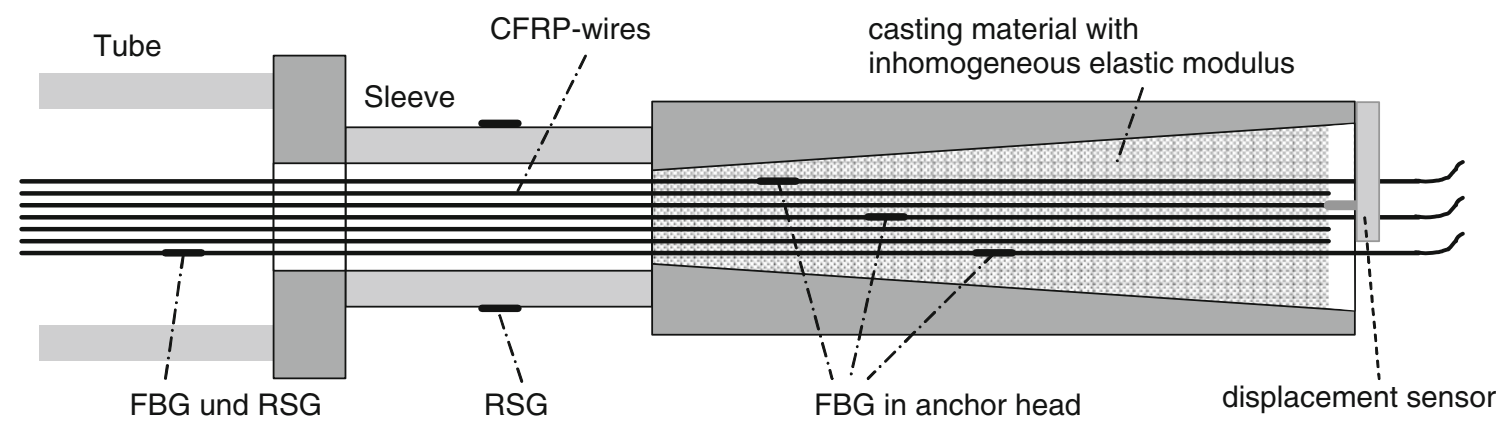

Fig. 10 Longitudinal section of the CFRP cable anchorage with RSG and FBG sensors on the steel sleeves and the CFRP-wires-inside and outside of the anchor head 
RSGs on CFRP-wire applications. Due to a defective amplifier there is a lack of data during the years 2008 and 2009.

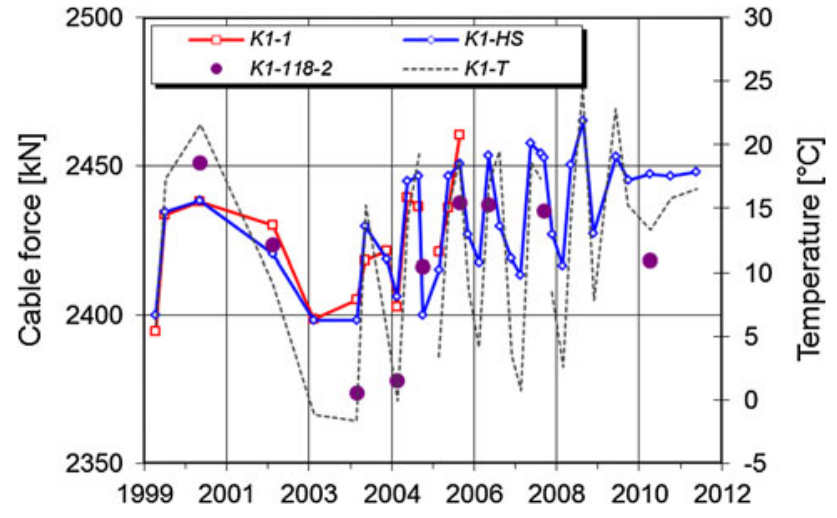

Fig. 11 Cable force obtained from measurements with FBGs (K1118-2) and RSGs (K1-1) and the sleeve (K1-HS) on the CFRP-wires

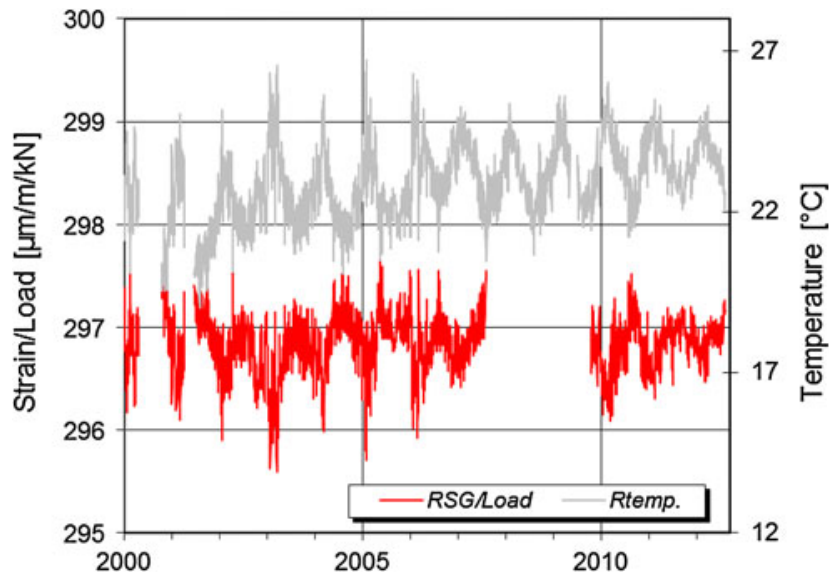

Fig. 12 Strain to load ratio of the reference measurement on the CFRP-wire with a constant load of $32 \mathrm{kN}$
2.3 Bridge sul Ri di Verdasio, Centovalli (Switzerland)

During operation of this 70 -m-long bridge the steel posttensioning cables partially corroded. Therefore, the bridge was retrofitted with four additional CFRP-cables (Fig. 13). Each cable is prestressed with $600 \mathrm{kN}$, which induces very high strains in each of the 19 CFRP-wires of up to $9,500 \mu \mathrm{m} / \mathrm{m}$. Here, the eight anchor heads were equipped with RSGs and the pull-in of the CFRP wires into the head was measured with a caliper gauge (Fig. 14).

Since no sensors had been installed on the CFRP-wires, the RSGs applied on the sleeve-half were calibrated in a force test

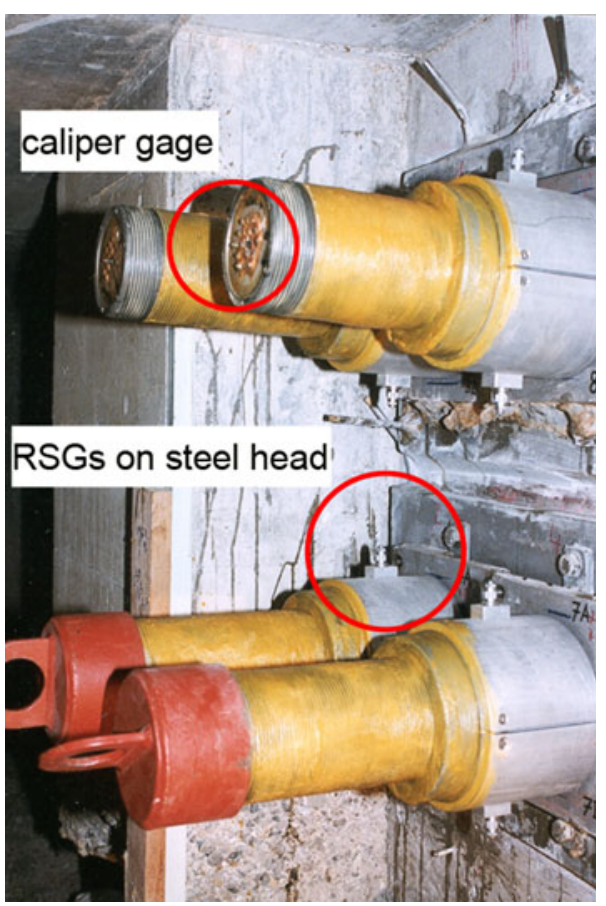

Fig. 14 Anchorage of the four CFRP-cables where the forces and the pull-in of the CFRP-wires are measured
Fig. 13 The retrofitted 70-mlong bridge sul Ri di Verdasio

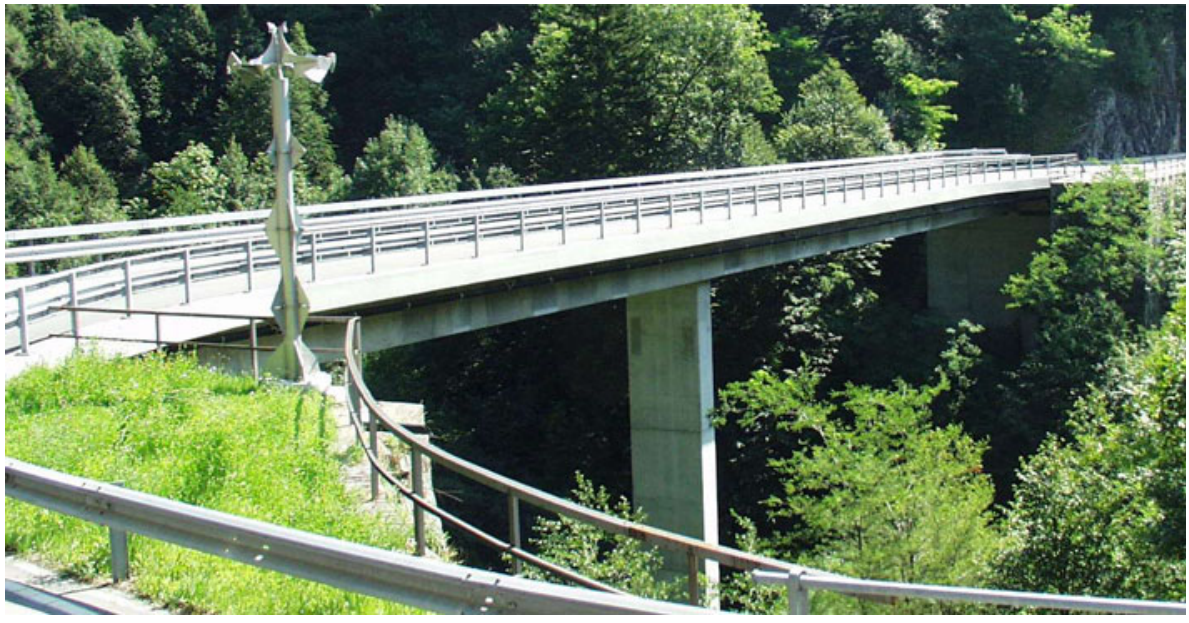




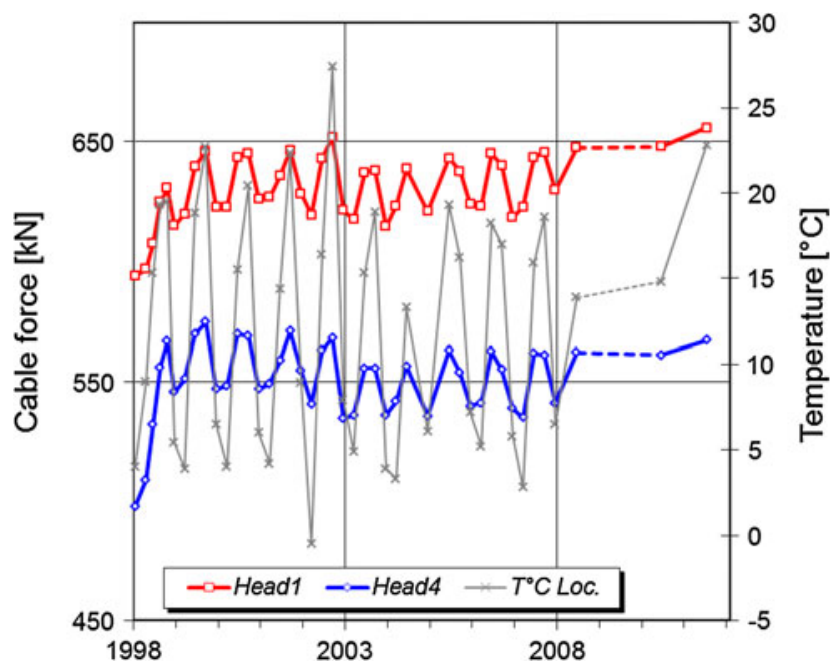

Fig. 15 Typical data of the force measurement on both anchor heads of one CFRP-cable

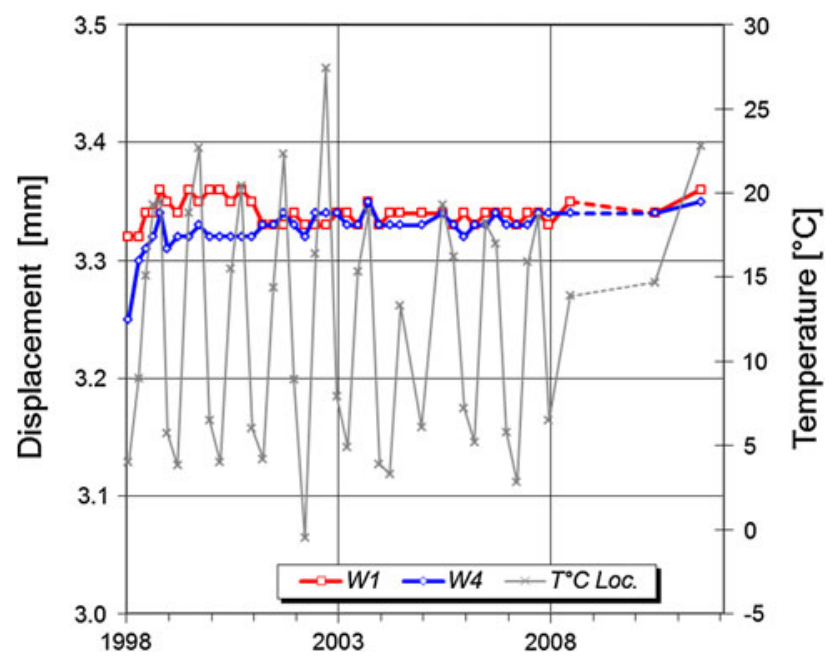

Fig. 16 Typical data of the displacement measurement (W1 and W2) on both anchor heads of one CFRP-cable

machine. The scattering of this calibration shows a bandwidth of $1 \%$ of the effective forces. This accuracy is sufficient to measure relevant changes of the pretensioning forces. Moreover, the force effects due to the seasonal temperature changes can be recorded reliably. Figure 15 shows the manual read-out of the forces for the two anchor heads of one of the four cables, while Fig. 16 shows the measurements of the pull-in of the CFRP parallel bundle into the anchorage cone. The observed increase of the forces and displacements at the beginning of the monitoring is due to the completion of the bridge with the installation of additional parts.

\section{Conclusions}

On three bridges with CFRP-cables, tensioning forces and displacements were measured with different measuring techniques. Well-established RSGs and LVDTs as well as newly developed FBG sensors have been in service for up to 17 years. To obtain information regarding the long-term reliability, reference sensors and redundant sensing systems have been installed, allowing one to differentiate between sensor drift and changes in the performance of the CFRP-cables. Additional long-term laboratory experiments have helped to validate sensing systems. At the Storchenbruecke, no FBG-failure occurred in 230 cumulated operation years while at the Bridge Kleine Emme, 8 of 21 FBGs failed in 240 cumulated operation years. Even though similar sensing techniques have been applied, the reliability of the installation on the Storchenbruecke is much higher. Not only the lower strain level but also the better established application technique is responsible for the remarkable reliability and a lifetime comparable to that of the bridge can be achieved.

That usually some parts, e.g., RSGs, cannot be replaced without losing baseline information is a major difficulty. Approaches to solve this problem are to include means to set the sensing system in a well-defined state to regain the baseline or to include adequate redundancy. Still, wellplanned sensing systems, verified methods and careful installation result already now in suitable long-term monitoring systems for infrastructure.

\section{References}

1. Meier U, Brönnimann R, Anderegg P, Terrasi G (2012) 20 years of experience with structural health monitoring of objects with CFRP components, nondestructive testing of materials and structures. Springer, Berlin, pp 959-976, ISBN 978-94-007-07221

2. Harik I, Peiris A (2012) Case studies of structural health monitoring of bridges, nondestructive testing of materials and structures. Springer, pp. 1007-1013, ISBN 978-94-007-0722-1

3. Brönnimann R, Terrasi G (2009) Strain monitoring by resistance measurement of carbon fiber prestressing tendons in filigree high performance concrete elements. ISHMII conference, Zürich

4. Cusson D, Lounis Z, Daigle L (2011) Durability monitoring for improved service life predictions of concrete bridge decks in corrosive environments. Comput-Aided Infrastruct Eng 26:524-541

5. Andrea Del Grosso, Inaudi D, Pardi L (2002) Overview of European activities in the health monitoring of bridges, first international conference on bridge maintenance, safety and management. IABMAS, Barcelona

6. Anderegg $\mathrm{P}$, Brönnimann $\mathrm{R}$, Meier $\mathrm{U}$, Zuverlässigkeit von Messdaten bei der Langzeitüberwachung von Infrastrukturen, Experimentelle Untersuchungen von Baukonstruktionen, 6. Symposium, (2011), TU Dresden, pp 163-174, ISSN 1613-6934

7. Habel WR (2005) Stability and reliability of fiberoptic measurement systems-basic conditions for successful longterm structural health monitoring, sensing issues in civil structural health monitoring. Springer, pp 341-351

8. Anderegg P, Brönnimann R, Phillip M. Nellen, Sennhauser U (2002) Reliable long-term monitoring of CFRP cables in bridges, 
international workshop on structural health monitoring of innovative civil engineering structures, Winnipeg (CND)

9. Mauron P (2001) Reliability and life time of optical fibres and fibre gratings for metrology and telecommunications. Thesis EPF No 2339, Lausanne, ISBN 3-905594-24-2

10. Frank A (2001) Dehnungs- und Temperaturmessung in Verbundwerkstoffen mit eingebetteten faseroptischen Bragg-GitterSensoren. Dissertation ETH Nr. 14083, Zürich, ISBN 3-90559426-9

11. Saccomanno A, Armando Laudati A, Szillasi Z, Beni N, Cutolo A, Irace A, Giordano M, Buontempo S, Cusano A, Breglio G (2012) Long-term temperature monitoring in CMS using fiber optic sensors. IEEE Sensors 12(12):3392-3398

12. Samaras VA, Fasl J, Reichenbach M, Helwig T, Wood S, Frank K (2012) Long-term gage reliability for structural health monitoring of steel bridges. In: Proceedings of the SPIE 8347 83471Q-1

13. Sennhauser U, Anderegg P, Brönnimann R, Nellen Ph M (1997) Monitoring of stork bridge with fiber optic and electrical resistance sensors. US-CND-EU-workshop on bridge engineering, Zürich

14. Nellen Ph M, Anderegg P, Brönnimann R, Sennhauser U (1997) Application of fiber optic and resistance strain gauges for long- term surveillance of civil engineering structures. In: SPIE Symposium on smart structures and materials, San Diego, vol 3043

15. Zhu H-H, Ho ANL, Yin J-H, Sun HW, Pei H-F, Hong C-Y (2012) An optical fibre monitoring system for evaluating the performance of a soil nailed slope. Smart Struct Syst 9(5):393-410

16. Ramzyzan R, Wahyu K, Rahman MKA (2012) Using embedded fiber bragg grating (FBG) sensors in smart aircraft structure materials. Proc Eng 41:600-606

17. Majumder M, Gangopadhyay TK, Chakraborty AK, Dasgupta K, Bhattacharya. K (2008) Fibre bragg gratings in structural health monitoring-present status and applications. Sensors Actuators A 147:150-164

18. Chana THT, Yua L, Tamb HY, Nia YQ, Liub SY, Chungb WH, Chengc LK (2006) Fiber bragg grating sensors for structural health monitoring of Tsing Ma bridge: background and experimental observation. Eng struct 28(5):648-659

19. Tennyson RC, Mufti AA, Rizkalla S, Tadros G, Benmokrane B (2001) Structural health monitoring of innovative bridges in Canada with fiber optic sensors. Smart Mater Struct 10:560-573 